\title{
Microstructure and Mechanical Properties of Annealed WC/C PECVD Coatings Deposited Using Hexacarbonyl of $W$ with Different Gases
}

\author{
Peter Horňák ${ }^{1,2}$, Daniel Kottfer ${ }^{3, *} \oplus$, Karol Kyzioł ${ }^{4} \oplus$, Marianna Trebuňová ${ }^{5} \oplus$, \\ Janka Majerníková $^{3}{ }^{\circledR 0}$, Łukasz Kaczmarek ${ }^{6}$, Jozef Trebuňa ${ }^{3}$, Ján Hašul ${ }^{3}$ and Miroslav Pal'o ${ }^{3}$ \\ 1 Department of Materials Science, Faculty of Industrial Technologies, Alexander Dubček University of Trenčín, \\ I. Krasku 491/30, 02001 Púchov, Slovakia; hornak.peter@gmail.com \\ 2 Institute of Materials Research, Slovak Academy of Sciences, Watsonova 47, 04001 Košice, Slovakia \\ 3 Department of Mechanical Technologies and Materials, Faculty of Mechanical Engineering, \\ Technical University of Košice, Mäsiarska 74, 04001 Košice, Slovakia; janka.majernikova@tuke.sk (J.M.); \\ jozef.trebuna@gmail.com (J.T.); jan.hasul@tuke.sk (J.H.); m.palo@commercservice.sk (M.P.) \\ 4 Department of Physical Chemistry and Modelling, Faculty of Materials Science and Ceramics, \\ AGH University of Science and Technology, A. Mickiewicza 30 Av., 30-059 Kraków, Poland; \\ kyziol@agh.edu.pl \\ 5 Department of Biomedical Engineering and Measurement, Faculty of Mechanical Engineering, \\ Technical University of Košice, Letná 9, 04200 Košice, Slovakia; marianna.trebunova@tuke.sk \\ 6 Institute of Materials Science and Engineering, Lodz University of Technology, 1/15 Stefanowskiego Str., \\ 90-924 Łódź, Poland; lukasz.kaczmarek@p.lodz.pl \\ * Correspondence: daniel.kottfer@tuke.sk; Tel.: +421-55-602-3514
}

Received: 30 June 2020; Accepted: 6 August 2020; Published: 13 August 2020

check for updates

\begin{abstract}
The present work studies the tungsten carbide (WC/C) coatings deposited by using Plasma Enhanced Chemical Vapor Deposition (PECVD), with and without gases of Ar and $\mathrm{N}_{2}$. Volatile hexacarbonyl of $\mathrm{W}$ was used as a precursor. Their mechanical and tribological properties were evaluated. The following values were obtained by using deposition process with $\mathrm{N}_{2}$ of $\mathrm{H}_{\mathrm{IT}}=19.7 \pm 4.1 \mathrm{GPa}, \mathrm{E}_{\mathrm{IT}}=221 \pm 2.1 \mathrm{GPa}$, and coefficient of friction $(\mathrm{COF})=0.35 \pm 0.09$. Secondly, deposition without the aforementioned gas obtained values of $\mathrm{H}_{\mathrm{IT}}=20.9 \pm 2 \mathrm{GPa}, \mathrm{E}_{\mathrm{IT}}=292 \pm 20 \mathrm{GPa}$, and $\mathrm{COF}=0.69 \pm 0.05$. WC/C coatings were annealed at temperatures of 200,500 , and $800{ }^{\circ} \mathrm{C}$, respectively. Evaluated factors include the introduced properties, the observed morphology, and the structural composition of WC/C coatings. The process of degradation was carried out by using various velocities, depending on used gases and annealing temperatures.
\end{abstract}

Keywords: coating; PECVD; tungsten carbonyl; annealing; mechanical properties; tribological properties

\section{Introduction}

Tungsten carbide is oftentimes used in the thin coating form and is known as a solution with high hardness and durability against abrasive wear. Due to the already mentioned properties, WC/C coatings have a low coefficient of friction (COF) and are used as a protection of functional surfaces of mechanical components made out of steels and for coating of high-speed steels, as well as hard metals. WC coatings are deposited by using PVD (Physical Vapor Deposition) and CVD (Chemical Vapor Deposition) methods concerning the high temperature of fusion of WC (ca. $\left.2550{ }^{\circ} \mathrm{C}\right)$ [1]. Out of all PVD methods, the most used methods are direct current magnetron sputtering (DCMS) [2-10] and radiofrequency magnetron sputtering (RFMS) [9,11-15] with Ar. Reactive sputtering of W, C, or WC from a target, in the presence of hydrocarbon [2] or other added gases [3,4,14], is used, too. 
Other effective methods of sputtering include High Target Utilization Sputtering (HiTUS) [15] and High-Power Impulse Magnetron Sputtering (HiPIMS) [3]. WC coatings can be deposited by using the CVD method [16,17]. A disadvantage of the CVD method is its high depositing temperatures, ranging from 800 to $1200{ }^{\circ} \mathrm{C}$, which exclude, for example, aluminum alloy from being coated. It is often necessary, following the process of coating of steels, to provide thermal treatment of said coatings. Gesheva et al. [18], using pyrolytic decomposition of $\mathrm{W}(\mathrm{CO})_{6}$, at $400^{\circ} \mathrm{C}$, in argon atmosphere, deposited WC thin films on Si substrate. Gesheva et al. also deposited polycrystalline W films [18], using hydrogen reduction of $\mathrm{WCl}$ at $750{ }^{\circ} \mathrm{C}$, in $\mathrm{Ar}$ atmosphere. The deposition of coatings by the decomposition of W and Mo carbonyls, using the CVD technique, has been published in References [18,19], and the same process by the decomposition of Cr carbonyl in Reference [20]. Gesheva et al. [18] obtained thicknesses of the WC coatings ranging from 0.12 to $0.6 \mu \mathrm{m}$ and MoC coatings from 0.12 to $0.3 \mu \mathrm{m}$. The temperature of deposition was from 340 to $400^{\circ} \mathrm{C}$. Electric properties were evaluated. Sagalovich et al. [19] deposited $\mathrm{MoC}$ coatings in the temperatures from 480 to $540{ }^{\circ} \mathrm{C}$ and pressures in the vacuum chamber ranging from 9 up to $16 \mathrm{~Pa}$. The hardness of the obtained $\mathrm{MoC}$ coating was situated in an interval from 11 to $18 \mathrm{GPa}$, while the thickness was presented by using the cross-sectional scanning electron microscopy (SEM) view of the pictures, from 143 to $173 \mu \mathrm{m}$. A CrC coating was deposited by Erokhin et al. [20], using the process of decomposition of Cr carbonyl. Hardness was equal to $17 \mathrm{GPa}$; meanwhile, the thickness of the coating was not stated. The PECVD method involves using Ar to create low-pressure and low-temperature plasma, which enables the deposition of a coating in temperatures up to $500^{\circ} \mathrm{C}$, where $\mathrm{W}$ hexacarbonyl [21-24] has been used as a precursor. Usoltsev et al. [25] explored the process of creation and decomposition of $\mathrm{W}(\mathrm{CO})_{6}$ and $\mathrm{Mo}(\mathrm{CO})_{6}$. Rezuchina and Švyrev [26] and Garner et al. [27] researched the pressure of saturated gases and their sublimation temperatures. The dependence of pressure of $\mathrm{W}(\mathrm{CO})_{6}$ gases on temperature, according to Garner et al. [27] and Chelappa and Chandra [28], is given by the following equation: $\log p=10.65-(3872 / \mathrm{T})$, where $p$ is pressure in $\mathrm{kPa}$, and $T$ is the absolute temperature in $\mathrm{K}$. Pressure of $\mathrm{W}(\mathrm{CO})_{6}$ gases, in temperatures ranging from 20 to $40{ }^{\circ} \mathrm{C}$, ranges from 2.7 to $19 \mathrm{~Pa}$. This comes as a result of the equation above. This is also allowing us to achieve relatively high velocities of sublimation while working pressures in the chamber of the PVD apparatus are ranging from 0.01 to $10 \mathrm{~Pa}$. In the aforementioned, it is also implied that the usage of carrier gas is not necessary. The temperature of the decomposition of $\mathrm{W}(\mathrm{CO})_{6}$ is $170{ }^{\circ} \mathrm{C}$ [21]. Dependence of coefficient of friction (COF) and $\mathrm{H}_{\mathrm{IT}} \mathrm{WC} / \mathrm{C}$ coatings on the content of $\mathrm{C}$ in the coating and dependence of $\mathrm{H}_{\mathrm{IT}}$ and $\mathrm{COF}$ on the volume of $a-\mathrm{C}$ in the WC/C coating have been identified by El Mrabet et al. [9]. Gases such as $\mathrm{H}_{2}$ [2,22] and $\mathrm{C}_{2} \mathrm{H}_{2}$ [22] are often used to affect the mechanical and tribological properties of WC/C coatings. Other effective gases and mixtures of gases are not used very often in the process of deposition of WC/C coatings using PVD and CVD methods, since there is a lack of information about such description phenomena in the literature. The usage of $\mathrm{W}$ carbonyl for deposition of WC/C PECVD coatings and evaluation of their properties $(\mathrm{H}, \mathrm{E}$, and $\mathrm{COF})$ is not published fairly often, too. That is the reason why $\mathrm{W}(\mathrm{CO})_{6}$ has been used as a precursor and added gases Ar or $\mathrm{N}_{2}$ in the process of deposition of WC/C coating, using the PECVD method. This work aimed to evaluate the effect of temperature on the thermal stability, hardness, Young's modulus, and COF of the WC/C coatings, with and without the added gases, such as Ar and $\mathrm{N}_{2}$. Obtained results were compared with other published results and results from articles published by us $[4,14]$, to which this work relates.

\section{Materials and Methods}

\subsection{Sample Preparation}

Two types of samples were prepared. Samples of a monocrystal of Si with approximate size $20 \times 15 \times 1 \mathrm{~mm}$ were used to evaluate the thickness and structure of WC/C coatings via scanning electron microscopy (SEM) JEOL JSM 7000F Tokyo, Japan. The sample can be easily broken post-deposition. The breakage must be carried out in a manner wherein the coating is exerted by using pulling forces. 
Afterward, the breakage can be inspected by using SEM. Samples for tribological tests were made out of steel C45 (STN 412050). The chemical composition (wt.\%) of steel samples was per Technical Standards (STN EN 412050): $0.42-0.50 \% \mathrm{C}$, $\max 0.40 \% \mathrm{Si}, 0.50-0.80 \% \mathrm{Mn}, \max 0.40 \% \mathrm{Cr}$, $\max 0.10 \%$ Mo, $\max 0.40 \% \mathrm{Ni}, \max 0.035 \%$, and $\max 0.035 \%$ [4]. Samples were made by using wire electrical discharge machining (WEDM) from bars of circular cross-section profiles with diameters of 50 and $25 \mathrm{~mm}$. Function surfaces were machined to a thickness of $3.00 \pm 0.05 \mathrm{~mm}$. The substrate was tempered in oil to the temperature of $860{ }^{\circ} \mathrm{C}$, followed by annealing at the temperature of $200{ }^{\circ} \mathrm{C}$. Following heat treatment, the substrates were polished in a diamond paste with the granularity of 15,9 , and $3 \mu \mathrm{m}$. Subsequently, the substrates were polished specularly by $1 \mu \mathrm{m}$ of diamond paste, to the final roughness of the surface being $R_{a} c a .12 \mathrm{~nm}$. The substrates were then purified with ultrasound, in an acetone environment for $10 \mathrm{~min}$, and dried with an electric hairdryer for $5 \mathrm{~min}$. After that, the substrates were inserted into the vacuum chamber. Before deposition of the coating and after draining the vacuum chamber, the substrates were cleaned by etching in argon, in glow discharge. The parameters of the cleaning process were as follows [4]: pressure (2 Pa), bias of the holder $\mathrm{U}_{\mathrm{b}} c a .-5 \mathrm{kV}$; and current density to the substrate samples $\left(1 \mathrm{~mA} \cdot \mathrm{cm}^{-2}\right)$ and the time of cleaning $(15 \mathrm{~min})$. In addition, Ar with a flow of $65 \mathrm{~cm}^{3} \cdot \mathrm{min}^{-1}$ was blown into the vacuum chamber.

\subsection{Deposition of Coatings and Annealing}

A ZIP 12 device was used for deposition of the WC/C coating with sublimation chamber (Scheme 1). The PECVD method was used with direct current. Moreover, the negative electric potential was connected to electrically conductible substrates against the metallic vacuum chamber of the PVD apparatus. An auxiliary anode was located in the chamber. The substrates were placed onto the substrate holder; the crucible and the precursor were placed into the sublimation chamber and enclosed by a valve between sublimation chamber and vacuum chamber. After the cleaning procedure and ensuring the required yield pressure, which was $c a .10^{-3} \mathrm{~Pa}$, the deposition of WC/C coating was carried out. Relating to the experiment presented in this paper, argon (Ar) with a purity of $99.999 \%$ was used as a carrier gas.

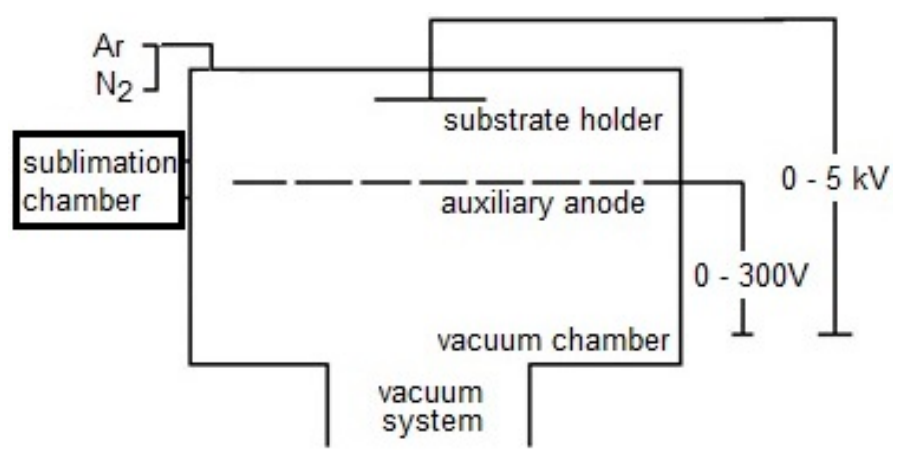

Scheme 1. The PECVD device type ZIP 12 with sublimation chamber.

The valve between the sublimation and vacuum chamber was opened. Pulverized volatile $W(C O)_{6}$ (W hexacarbonyl) was used as a precursor for the PECVD process of deposition of the WC/C coating. During the process, the sublimation of vapors of $\mathrm{W}(\mathrm{CO})_{6}$ (it is based on the chamber vacuum and temperature of precursor $[27,28]$ ) into the surroundings between substrate holder with substrates and auxiliary anode, where these vapors ionize (ionized gas is also called low-pressure, low-temperature plasma). Ionized particles of the sublimed precursor were accelerated at a substrate passing through the plasma.

Decomposition of $\mathrm{W}(\mathrm{CO})_{6}$ to $\mathrm{W}+6 \mathrm{CO}$ and $2 \mathrm{CO} \rightarrow \mathrm{C}+\mathrm{CO}_{2}$ reaction takes place in the plasma area and on the surface of the substrate. Carbon created in this manner reacts with tungsten and creates tungsten carbide. The real mechanism of the decomposition created by the collision of $\mathrm{W}(\mathrm{CO})_{6}$ 
molecules with electrons and their ions is significantly more difficult and the existence of $\mathrm{W}(\mathrm{CO})_{6}$ fragments of the decomposition in the excited and ionized state can be assumed.

For control of the deposition temperature, the substrates were covered with Kapton tape before the deposition of the WC/C coating. Kapton tape is made out of polyimide with a silicone sticking surface on one side. It is characterized by heat-resistance, depending on the manufacturer, up to the temperature of $350{ }^{\circ} \mathrm{C}$.

Annealing of samples with WC/C coating was carried out by inserting the substrates into an electric oven, at temperatures of 200,500 , and $800{ }^{\circ} \mathrm{C}$, without the protective atmosphere, for $1 \mathrm{~h}$. After that, the oven was turned off, and the substrates cooled down naturally. Annealing at a temperature of $200{ }^{\circ} \mathrm{C}$ was carried out only to assure the effect of inner tension on the indentation hardness.

\subsection{Nanohardness and Young's Modulus}

$\mathrm{H}_{\mathrm{IT}}$ hardness and indentation module $\mathrm{E}_{\mathrm{IT}}$ on the coated substrates were explored by using instrumented indentation on nano hardness tester (NHT), CSM Instruments, Basel, Switzerland on steel substrates. The conditions of measurements were as follows: sinus mode with $1 \mathrm{mN}$ amplitude, encumbered strength was established according to the thickness of the coating in an interval from 20 to $60 \mathrm{mN}$, frequency $15 \mathrm{~Hz}$. A diamond Berkovich indenter was used. Ten measurements were carried out on all of the WC/C coatings. Curves with an extreme course were excluded from the analyses. Values of indentation hardness and indentation module were calculated as an average of maximal values of indentation curves.

\subsection{SEM, AFM, XRD, and GDOES Analyses}

Thickness, the morphology of the surface of the evaluated coatings, and their microstructure were observed by an electron microscope JEOL JSM 7000 F, Tokyo, Japan.

Chemical analysis was evaluated as the depth of the chemical concentration profile, using the Glow Discharge Optical Emission Spectroscopy (GDOES) technique (Leco Corporation, St. Joseph, MI, USA). During this analysis, the Spectruma GDA 750 equipment was applied, which is provided with a monochromator with a Czerny-Turner design (focal length of $480 \mathrm{~mm}$ ). The spatial resolution of the monochromator was $0.025 \mathrm{~nm}$.

The phase composition of WC/C coatings was measured by using diffraction analysis. The spectrums were gauged by a diffraction meter X'Pert PRO Philips, Eindhoven, Netherland with a detector $X^{\prime}$ Celerator in Bragg-Brentanto parafocusational arrangement with a regime of measurement $\theta / 2 \theta$. The source of RTG (X-ray diffraction) radiation was a copper cathode (I $=40 \mathrm{kV}$, $\mathrm{U}=50 \mathrm{~mA}$ ) with characteristic RTG radiation $\mathrm{CuK} \alpha_{1,2}$ in a wavelength $1.5418 \times 10^{-10} \mathrm{~m}$. XRD spectra were measured in a range of angles $10-100^{\circ}$, with a step length of $0.033^{\circ}$. Qualitative analysis was carried out with the help of the CMPR program, a power diffraction toolkit [29], and interpreted with the PDF-2 database [29].

The topography of the coated surface was measured by using an atomic force microscope (AFM), Dimension Icon, Veeco, Plainview, NY, USA.

\subsection{Coefficient of Friction}

The COF of WC/C coatings prepared on steel substrates was measured by a Ball-on-Disc method, using a high temperature tribometer (HTT), CSM Instruments, Needham, MA, USA, in a load of $0.5 \mathrm{~N}$ and room air temperature of $21^{\circ} \mathrm{C}$. A steel ball $100 \mathrm{Cr} 6$ with a diameter of $6 \mathrm{~mm}$, a velocity of $10 \mathrm{~cm} / \mathrm{s}$, and a sliding distance of $50 \mathrm{~m}$ was used as a counterpart. The coefficient of friction and the depth of penetration of the substrate surface were continually noted down for each test as a function of time, a number of turnings, and distance. Wear of evaluated coatings and wear of the counterpart (ball) were not evaluated. 


\section{Results and Discussion}

The WC/C coatings were deposited in the following combinations: (i) optimization of the deposition parameters concerning the maximal hardness and minimal COF without the use of added gas (only using sublimed carbonyl of W), (ii) deposition of the optimized WC/C coating with added gas of Ar, and (iii) deposition of the optimized WC/C coating with added gas of $\mathrm{N}_{2}$. Each WC/C coating that was deposited with added gases was evaluated after deposition and after annealing at the temperatures of 200,500 , and $800^{\circ} \mathrm{C}$, respectively.

\subsection{Optimization of the Deposited Coatings' Parameters}

The results of the optimization of the deposition parameters considering maximal hardness and minimal COF value, without the usage of added gas, while only using sublimed gas W carbonyl, are below in Table 1.

Table 1. The selected technological parameters and properties of the optimized WC/C coatings with the use of $\mathrm{W}$ carbonyl as a precursor.

\begin{tabular}{|c|c|c|c|c|c|c|}
\hline $\begin{array}{c}\text { Sample } \\
\text { No. }\end{array}$ & $\begin{array}{l}\text { Pressure } \\
\text { (Pa) }\end{array}$ & $\begin{array}{c}\text { Bias } \\
(-k V)\end{array}$ & $\begin{array}{l}\text { Current Density } \\
\quad\left(\mathrm{mA} \cdot \mathrm{cm}^{-2}\right)\end{array}$ & $\begin{array}{l}\mathrm{H}_{\mathrm{IT}} \\
(\mathrm{GPa})\end{array}$ & $\begin{array}{c}\mathrm{E}_{\mathrm{IT}} \\
(\mathrm{GPa})\end{array}$ & COF (-) \\
\hline 1 & 2.0 & & \multirow{2}{*}{0.8} & 14.2 & 180 & - \\
\hline 2 & 3.0 & & & 16.7 & 294.5 & - \\
\hline 3 & 1.0 & 5 & \multirow{3}{*}{1.0} & 17.5 & 305 & 0.8 \\
\hline 4 & 2.0 & & & 17.3 & 292 & 0.25 \\
\hline 5 & 3.0 & & & 20.9 & 298 & 0.26 \\
\hline
\end{tabular}

Note: $\mathrm{COF}=$ coefficient of friction.

Table 1 shows that $\mathrm{H}_{\mathrm{IT}}$ values of WC/C coating deposited without $\mathrm{Ar}$ (carrier gas) were in an interval from 14.2 to $20.9 \mathrm{GPa}$. The highest measurement of hardness occurred at a pressure of $3.0 \mathrm{~Pa}$. $\mathrm{E}_{\mathrm{IT}}$ values were from the interval of 180-305 GPa.

The lowest value of Young's modulus was measured, while the pressure in the vacuum chamber was at $2.0 \mathrm{~Pa}$, and the highest was measured at $3.0 \mathrm{~Pa}$. Since bias voltage and current density were constant, it can be stated that pressure in the vacuum chamber has a detrimental effect on evaluated hardness and Young's modulus. This also applies to COF. The maximum value of COF was equal to 0.8 with a pressure of $1.0 \mathrm{~Pa}$, and the minimum value was equal to 0.23 with the pressure of $3.0 \mathrm{~Pa}$. The deposition parameters of the $\mathrm{WC} / \mathrm{C}$ coating with the maximum value of $\mathrm{H}_{\mathrm{IT}}$ were accepted for the next experiment.

Moreover, WC/C coatings were prepared with a carrier gas of Ar, or with an addition of $\mathrm{N}_{2}$. The total pressure of deposition was $3 \mathrm{~Pa}$ when no added gases were added (using only sublimated carbonyl). For deposition with added gases in the chamber ( $\mathrm{Ar}$ or $\mathrm{N}_{2}$ ), the pressure was 2 or $4 \mathrm{~Pa}$. The ratio of partial pressures of added gases and the precursor was 1:1. The same amount of precursor was used for the preparation of coatings $-5 \mathrm{~g}$. The time duration of the deposition was $2 \mathrm{~h}$. Table 2 summarizes the specifications of the deposition and mechanical properties of the prepared coatings. The mentioned properties were evaluated before annealing.

Table 2. Deposition specifications and mechanical properties of WC/C PECVD coatings deposited with added gases.

\begin{tabular}{ccccccc}
\hline $\begin{array}{c}\text { Sample } \\
\text { No. }\end{array}$ & $\begin{array}{c}\text { Added } \\
\text { Gas }\end{array}$ & $\begin{array}{c}\text { Total Pressure } \\
(\mathbf{P a})\end{array}$ & $\begin{array}{c}\text { Gas Pressure } \\
\mathbf{( P a )}\end{array}$ & $\begin{array}{c}\mathbf{H}_{\mathrm{IT}} \\
\mathbf{( G P a )}\end{array}$ & $\begin{array}{c}\mathrm{E}_{\mathrm{IT}} \\
(\mathbf{G P a})\end{array}$ & $\begin{array}{c}\text { COF } \\
(-)\end{array}$ \\
\hline 6 & $\mathrm{Ar}$ & 2.0 & 1.0 & $28.5 \pm 2$ & $351 \pm 28$ & 0.8 \\
\hline 7 & $\mathrm{~N}_{2}$ & 4.0 & 2.0 & $19.7 \pm 4.1$ & $292 \pm 17$ & 0.59 \\
\hline
\end{tabular}




\subsubsection{Microstructure}

WC/C coatings evaluated by SEM analysis, prepared by using the PECVD method (Figure 1), on steel substrates without added gas, have a so-called cauliflower structure, as in Reference [23], with the size of cauliflower globulites ranging from $500 \mathrm{~nm}$ to $2.0 \mu \mathrm{m}$. The thickness of WC/C coatings was ca. The topography of coatings shown by using AFM confirmed the globulitic particles (Figure 2). Their creation is attributed to the circumstances of nucleation and the growth of coatings. The explanation for this kind of topography is the presence of grain structure in the lower part of grains, which are finished with the branching of globulite grains with the so-called cauliflower structure. These formations can be made out of substructures, such as nanocolumns or nanocauliflowers [23].

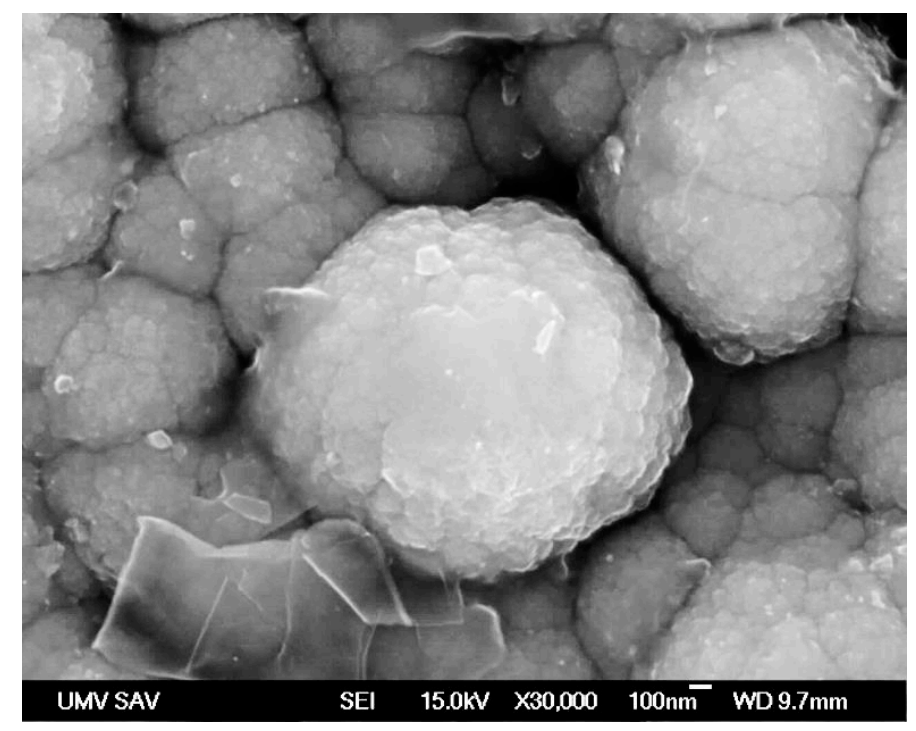

Figure 1. SEM image of the WC/C coating deposited on the steel substrate.

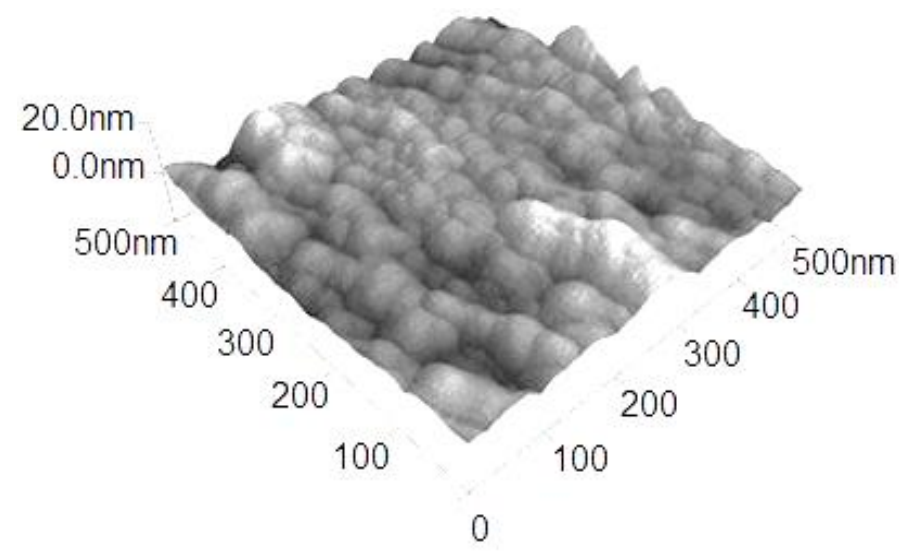

Figure 2. Topography (AFM image) of the WC/C coating.

\subsubsection{Indentation Hardness and Young's Modulus}

Figure 3 shows depth profiles of the indentation hardness course of examined WC/C coatings deposited with and without $\mathrm{Ar}$ (with maximum values of indentation hardness). All of the profiles show approximately the same course: The growth of the curves begins in extremely small depths with the hardness of $10 \mathrm{GPa}$. This growth reaches a maximum in depths of penetration $c a$. 50-60 nm, where the coatings' thickness was $c a .0 .7 \mu \mathrm{m}$. After that, the curves have a descending character. The peak of these curves should not be in the depth deeper than $1 / 10$ of the coating thickness. Therefore, the resulting value of indentation hardness will not be affected by the hardness of the substrate. The WC/C coating deposited with additive gas of Ar (obtained by optimization) has the highest indentation hardness, 
at $\mathrm{H}_{\mathrm{IT}}=28.5 \pm 2 \mathrm{GPa}$, and Young's modulus, at $\mathrm{E}_{\mathrm{IT}}=351 \pm 28 \mathrm{GPa}$. The hardness of a WC/C coating deposited with $\mathrm{N}_{2}$ is equal to $\mathrm{H}_{\mathrm{IT}}=20.9 \pm 2 \mathrm{GPa}$ and Young's modulus $\mathrm{E}_{\mathrm{IT}}=298 \pm 20 \mathrm{GPa}$. WC/C coatings prepared with argon in the PECVD process are reported to have the highest indentation hardness, $c a$. $28 \mathrm{GPa}$, which is correspondent to the hardness of WC/C coating with the content of $\mathrm{C}$ equal to $\mathrm{ca}$. 33\% [9]. Furthermore, the presence of $\mathrm{C}$ in the coating was not evaluated. It can be assumed, based on constant technological parameters of the WC/C coatings' deposition (time duration of the deposition was equal to $120 \mathrm{~min}$ ), that the thickness of the coating was close to the thickness of the coating deposited with added gases $\mathrm{Ar}$ and $\mathrm{N}_{2}$ (see Sections 3.2.1 and 3.3.1, respectively). Moreover, it can be expected that the thickness of the WC/C coating (deposited without Ar) is close to these values. The mentioned supports the development of hardness (Figure 3), where the maximum measured hardness is in depths of ca. $50 \mathrm{~nm}$.

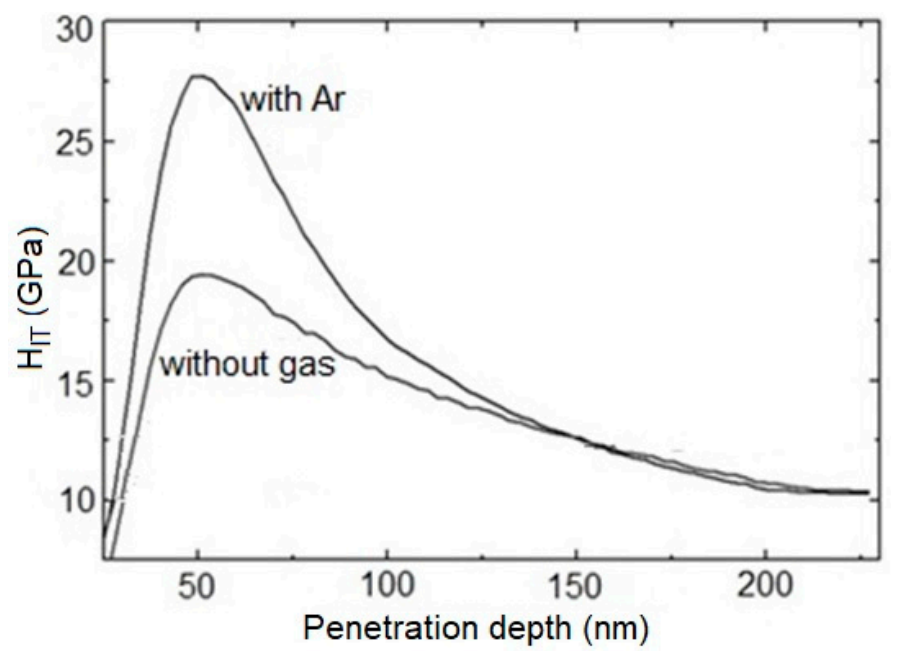

Figure 3. Depth profiles of the $\mathrm{H}_{\mathrm{IT}}$ of WC/C coatings.

\subsubsection{Coefficient of Friction}

The COF of the optimized WC/C coating reached the value of 0.26 (Figure 4), which corresponds with the $\mathrm{COF}$ of the WC/C coating with $c a .58 \%$ of $\mathrm{C}$ [9]. However, the content of $\mathrm{C}$ in the coating was not evaluated. Figure 4 exhibits the course of WC/C coating with $\mathrm{COF}=0.8$ which was deposited at the argon pressure of $1.0 \mathrm{~Pa}$. The coating's high value of hardness ( $c a .28 \mathrm{GPa}$ ) is accompanied with a high value of $\mathrm{COF}$, which can be attributed to the presence of WC and a lower content of graphite.

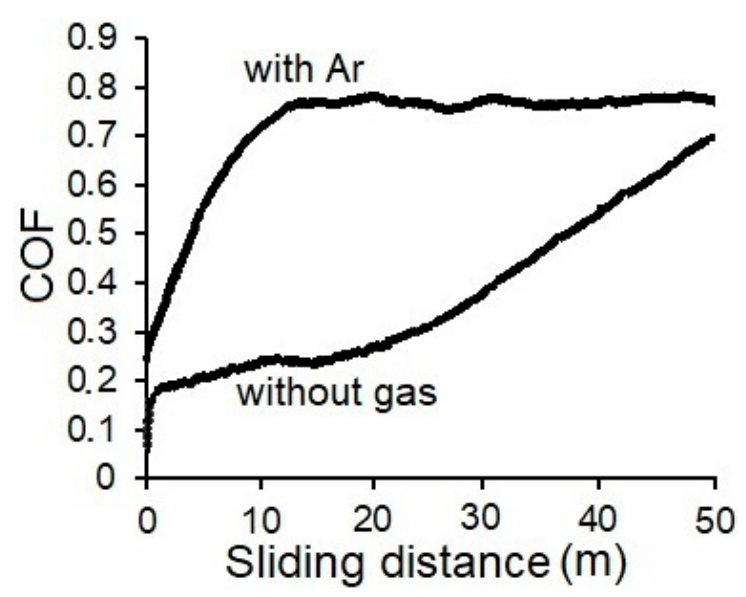

Figure 4. COF of WC/C coatings measured at room temperature (RT). 


\subsection{Ar Effect}

\subsubsection{Morphology, Phase Analysis, and Chemical Composition}

The surface reports a nano-column structure and presence of cauliflower globulites (see arrows) on the surface with size up to $100 \mathrm{~nm}$ (Figure 5a), while the cross-sectional view is pointing toward a dense columnar structure (Figure $5 \mathrm{~d}$ ). On the surface, following annealing with a temperature of $500{ }^{\circ} \mathrm{C}$, the globulite particles situated on the surface slightly thickened. However, the character of the surface remained the same. On top of that, clusters of particles with a size of $\approx 200 \mathrm{~nm}$ (Figure $5 \mathrm{~b}$-arrows) started to form locally. After annealing with the temperature of $800{ }^{\circ} \mathrm{C}$ (Figure $5 \mathrm{c}$ ), a visible disintegration of the structure occurred. Large spherical particles of $\mathrm{WO}_{3}$ with a diameter upward of $0.5 \mu \mathrm{m}$ can be spotted on the surface. An effect that is similar to the one on WC/C coating by depositing Ar [4] manifested. The dark places represent the surface without WC/C coating. These empty spots usually have size up to $50 \mathrm{~nm}$ (at some places, up to $100 \mathrm{~nm}$ ) and are recognizable even at a lower resolution. Empty spots are a consequence of WC/C coating disintegration. This disintegration is affected by the presence of chemical elements in the air. There is a rupture in the structure as a result of the swelling process-relating to the second phase, where $\mathrm{O}_{2}$ (penetrating the coating) reacts with $\mathrm{C}$ and $\mathrm{W}[30]$ to produce $\mathrm{CO}_{2}$ and $\mathrm{WO}_{3}$, respectively. The coating deposited with Ar is $0.7 \mu \mathrm{m}$ thick (Figure 5d).
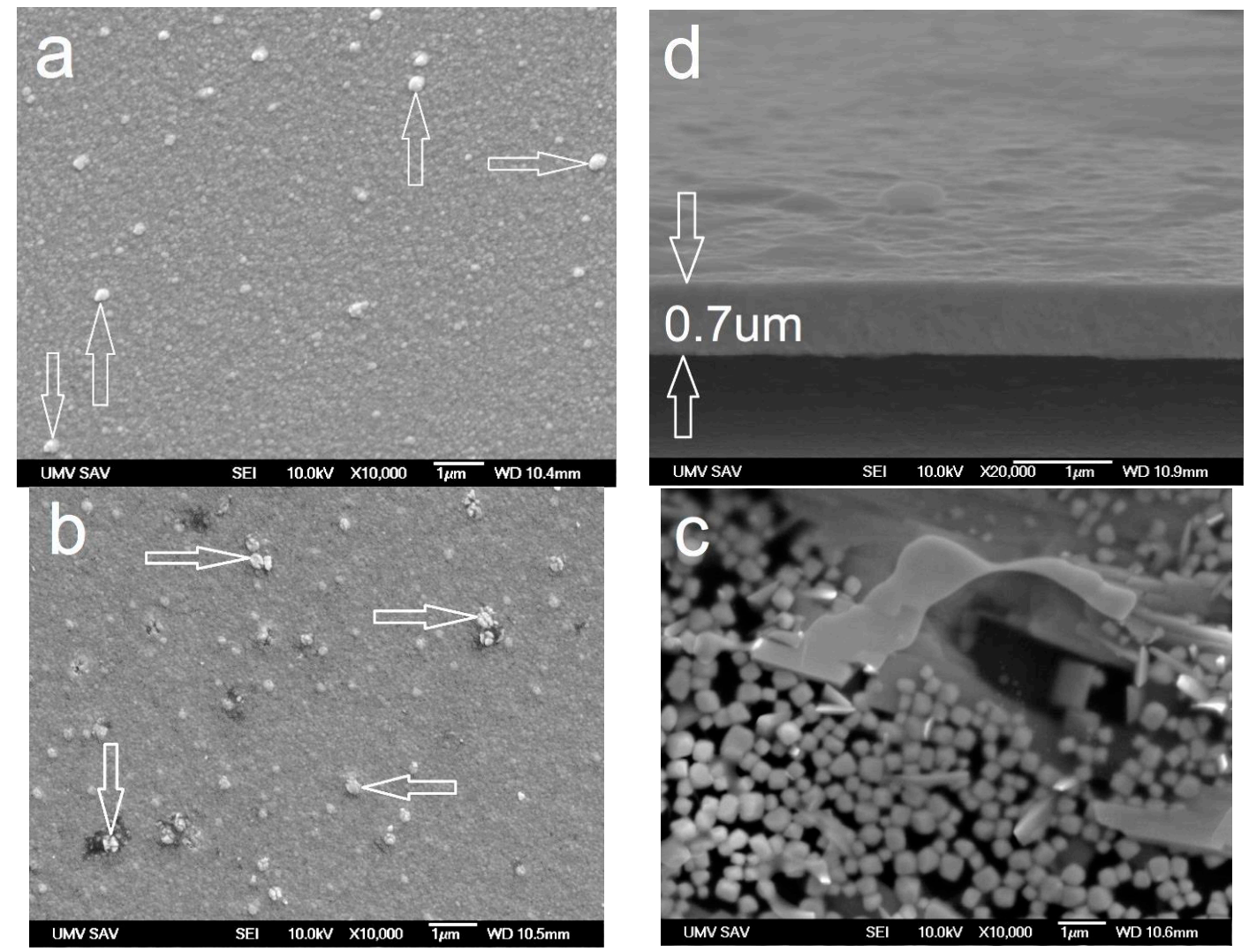

Figure 5. Morphology of the surface and cross-sectional brake of WC/C coating deposited with $\mathrm{Ar}$ (added gas): (a,d) RT and annealed at (b) $500{ }^{\circ} \mathrm{C}$ and (c) $800{ }^{\circ} \mathrm{C}(\mathrm{SEM})$.

The chemical composition of the deposited coating (Figure 6) shows that the amount of $\mathrm{W}$ ca. 95\% is constant on the surface of the coating down to the depth of ca. $0.45 \mu \mathrm{m}$. The content of $\mathrm{C}$ in the coating is linearly decreasing from ca. $44 \%$ on the surface down to ca. $20 \%$. 


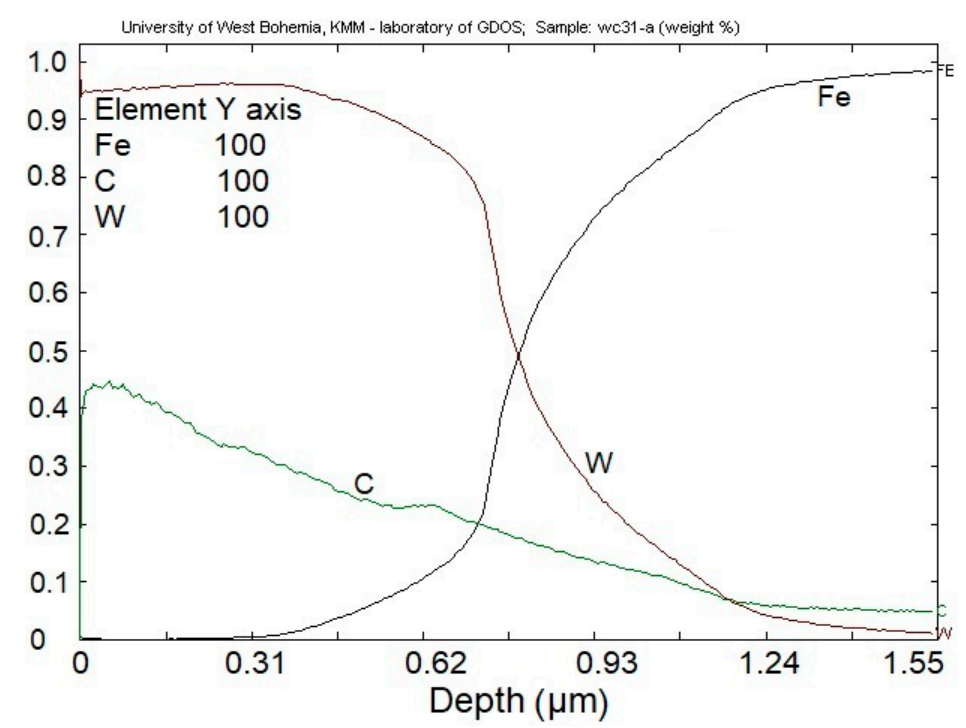

Figure 6. Cross-sectional chemical profiles of WC/C coating deposited with Ar.

Phase analysis of WC/C coating (Figure 7) in a non-annealed state (room temperature-RT) shows the presence of carbide phase $\mathrm{WC}_{1-\mathrm{x}}$ and $\mathrm{WO}_{3}$. After annealing at the temperature of $500{ }^{\circ} \mathrm{C}$, the structure undergoes amorphization. Only a subtle change of the intensity of the peaks occurs-a decrease of amorphous $\mathrm{WC}_{1-\mathrm{x}}$, as well as a $\mathrm{WO}_{3}$ peak. By annealing at the temperature of $800^{\circ} \mathrm{C}$ a significant reaction of the coating and the environment in the annealing furnace takes place. A sharp carbide phase of $\mathrm{WC}_{1-\mathrm{x}}$ and $\mathrm{WO}_{3}$ is present (respectively), as well as a bold phase of $\mathrm{W}_{2} \mathrm{~N}$ [30]. Given the fact that WC coatings crystallize at higher temperatures, a bold $\mathrm{W}_{2} \mathrm{~N}$ phase could appear in the structure, according to Choy K.L. [31].

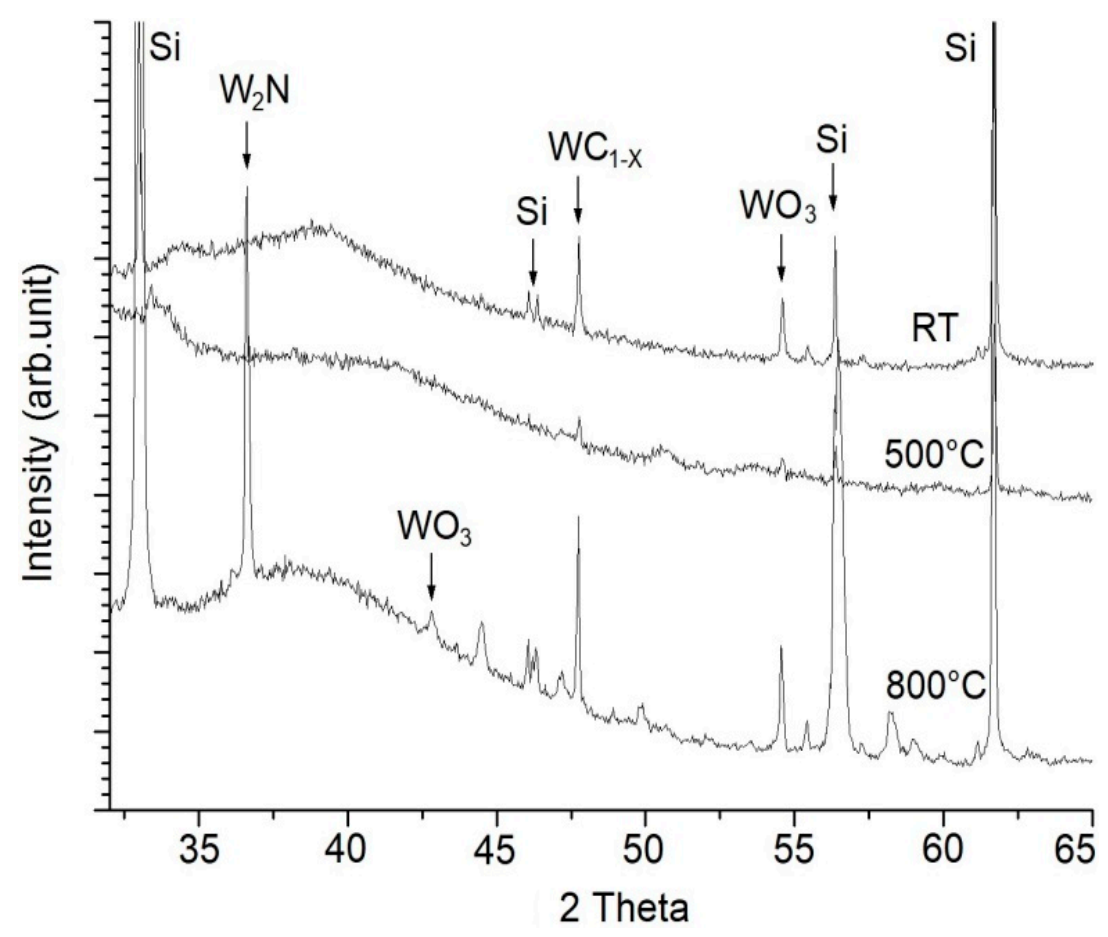

Figure 7. X-ray diffraction spectra of WC/C coatings at RT, after annealing at 500 and $800{ }^{\circ} \mathrm{C}$; Si phase. 


\subsubsection{Mechanical and Tribological Behavior}

$\mathrm{H}_{\mathrm{IT}}$ and COF of WC/C coatings, depending on annealing temperature, with and without doped gases, are presented in Figure 8. Ar as added gas caused the growth of hardness, as opposed to the coating deposited without the added gas. Hardness (RT) grew to $c a .28$ GPa (Figure 8a), which corresponds to the $\mathrm{H}_{\mathrm{IT}}$ of the WC/C coating with $\mathrm{C} c a$. 34\% [9], which also is a tabulated hardness of WC ca. $28 \mathrm{GPa}$ [1]. However, the evaluated coating contains ca. 44\% C (Figure 6). According to El Mrabet et al. [9], a WC/C coating with this amount of $C$ can have hardness equal to 18 or $32 \mathrm{GPa}$. The difference can be attributed to the presence of a-C in the coating and presence of carbide phase $\mathrm{WC}_{1-\mathrm{x}}$ (Figure 7). The achieved hardness ( $c a .28 \mathrm{GPa}$ ) is $33 \%$ lower when compared to Horńák et al. [4] $(37.2 \pm 4.8 \mathrm{GPa})$, who used the DCMS method with the carrying gas of $\mathrm{Ar}$, and $22 \%$ higher when compared to Horňák et al. [14] (22.2 $\pm 1.3 \mathrm{GPa})$, who used the RFMS method with the carrying gas of Ar.

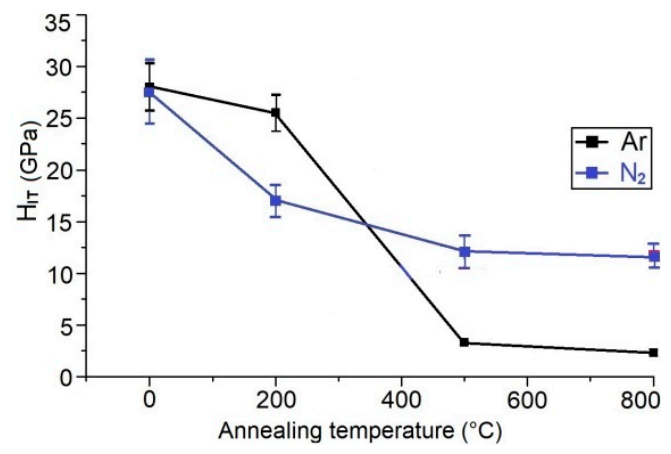

(a)

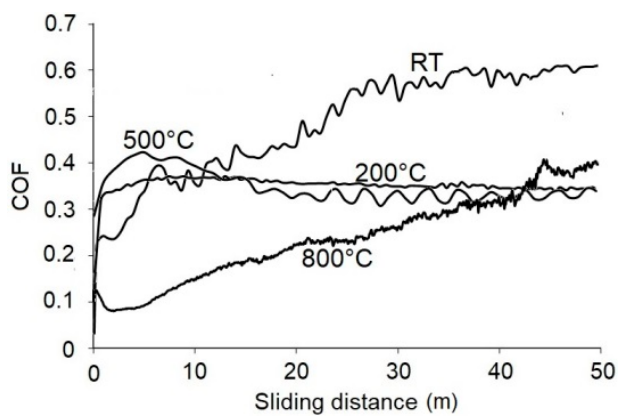

(c)

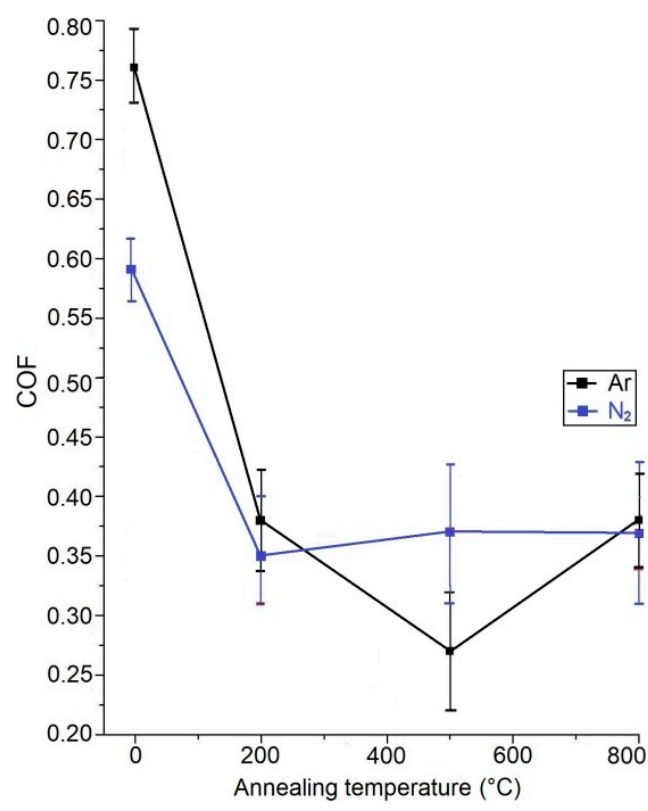

(b)

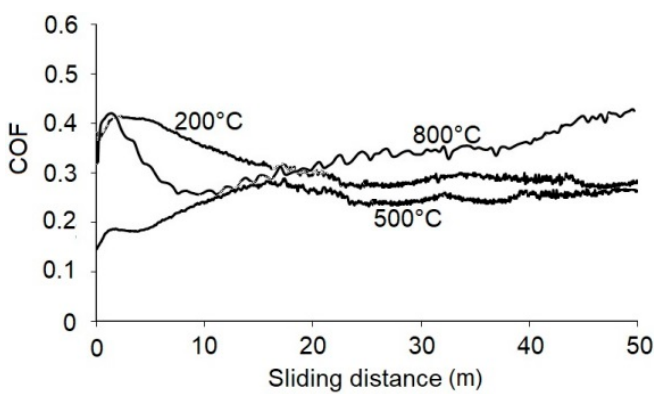

(d)

Figure 8. Dependence of $\mathrm{H}_{\mathrm{IT}}(\mathbf{a})$ and $\mathrm{COF}(\mathbf{b})$ vs. annealing temperature of the WC/C coatings deposited by using $\mathrm{Ar}$ or $\mathrm{N}_{2}$; $\mathrm{COF}$ curves vs. annealing temperature of the WC/C coatings deposited by using $\mathrm{N}_{2}$ (c) or $\operatorname{Ar}(\mathbf{d})$.

Ar was implemented during the deposition into the WC/C coating, which could have caused a significant growth of hardness as a result of the generated tensions to the crystal lattice. Nevertheless, the research on the amount of Ar in the coating has not been evaluated. The influence of Ar in the WC/C coating on the hardness and COF could be a topic for future research. 
Hardness slightly decreased to $26.0 \pm 1.5 \mathrm{GPa}$ after annealing at a temperature of $200{ }^{\circ} \mathrm{C}$, which is equal to the minimum measured value before annealing. On the other hand, after annealing at the temperatures of 500 and $800{ }^{\circ} \mathrm{C}$, the hardness of the WC/C coating has significantly decreased under 5 GPa (3.0 and 2.5 GPa-Figure 8a). These values are 50\% less than the values measured by Reference [4], yet in good agreement with Reference [14]. The hardness of WC/C coating after annealing at the temperature of $800{ }^{\circ} \mathrm{C}$ fits the status of its important disruption as a result of crystallization of the original amorphous structure, which fits Reference [5].

The COF value of the deposited WC/C coating with Ar grew to $0.77 \pm 0.02$ (Figure 4), which is three times more when compared with the coating deposited without Ar. It also is $26 \%$ more than what Hornák et al. reached, using DCMS [4] $(0.64 \pm 0.09)$ and close RFMS ( $c a .0 .82)$ methods. The value of $\mathrm{COF}$, which we measured, is close to the value given by El Mrabet, in Reference [9].

The high value of $\mathrm{COF}$ is a consequence of the value of $\mathrm{H}_{\mathrm{IT}}=28 \mathrm{GPa}$, which is also considered to be relatively high, when compared to the hardness of the counterpart (a sphere made out of steel 100Cr6) used in the tribotest. After annealing at the temperature of $200{ }^{\circ} \mathrm{C}$, COF has decreased to $0.36 \pm 0.06$ and after annealing at the temperature of $500{ }^{\circ} \mathrm{C}$, a tremendous decrease of the value of COF occurred, down to $0.27 \pm 0.05$. That is one-third more than in Reference [14], and $25 \%$ less when compared to Reference [4]. Ar inhibited the degradation of WC coating by swelling (Figure 5b). That could have caused the creation of a smaller contact surface between WC coating and the counterpart (ball) during the Ball-on-Disc test, which could have reduced the value of COF when compared with WC coating with $\mathrm{N}_{2}$ (Figure 8a).

COF increased to the value of $0.36 \pm 0.05$ after annealing at a temperature of $800{ }^{\circ} \mathrm{C}$, which is the same value as annealed at a temperature of $200^{\circ} \mathrm{C}$ (Figure $8 \mathrm{~b}$ ). A significant decrease of the COF after annealing at the temperatures of $500{ }^{\circ} \mathrm{C}$ (see Figure $8 \mathrm{c}$, using $\mathrm{N}_{2}$ ) and $800{ }^{\circ} \mathrm{C}$ (see Figure $8 \mathrm{~d}$, using Ar) could have been caused by the presence of $\mathrm{C}$ in the coating in the form of graphite. Another reason is a strong decrease in hardness of the evaluated coating after each process of annealing. Tribological properties of magnetron sputtered WC/C coatings, concerning the amount of $C$ in the coating, were evaluated by Mrabet et al. [9]. However, the determination of the amount of $C$ in the form of graphite is necessary. The mentioned criterion is often important when evaluating the sources of the increase/decrease of $\mathrm{H}_{\mathrm{IT}}$ and $\mathrm{COF}$ of the WC/C coatings obtained when using the PVD and/or CVD methods.

\section{3. $N_{2}$ Effect}

\subsubsection{Morphology}

As per Figure 9a, the surface of the WC/C coating is smooth, with column-like nanoparticles, with a diameter under $20 \mathrm{~nm}$. The cross-sectional view has confirmed this visible structure (Figure 9b). The thickness of the coating is $c a .0 .5 \mu \mathrm{m}$, while annealing at a temperature of $500^{\circ} \mathrm{C}$ caused a change in the morphology. Clusters of oxides formed, with the diameter ranging from $300 \mathrm{~nm}$ to $1 \mu \mathrm{m}$ (Figure 9c). Moreover, the thickness of the layer reached $c a .0 .7 \mu \mathrm{m}$ (Figure 9d). After annealing at the temperature of $800{ }^{\circ} \mathrm{C}$, oxidic clusters reached a diameter of $2.0 \mu \mathrm{m}$ and more (Figure 9e). Oxidation formed on the surface of the WC/C coating, with a thickness of $100 \mathrm{~nm}$, considering the total thickness of the layer being $c a .0 .7 \mu \mathrm{m}$ (Figure 9f).

Chemical composition of the coating (Figure 10) shows that the content of $\mathrm{W}$ is slightly decreasing from the surface of the coating, from the value of $c a .95 \%$ down to $c a .91 \%$. The presence of $C$ in the coating decreases linearly from the value of $c a .40 \%$ on the coating's surface, to $c a$. $20 \%$. The amount of $\mathrm{N}_{2}$ on the surface decreased $c a .5 \%$ down to the value of $c a .1 \%$ on the substrate-coating line. $\mathrm{O}_{2}$ is present only on the surface of the coating, which could be caused by oxidation of the coating in the air. 

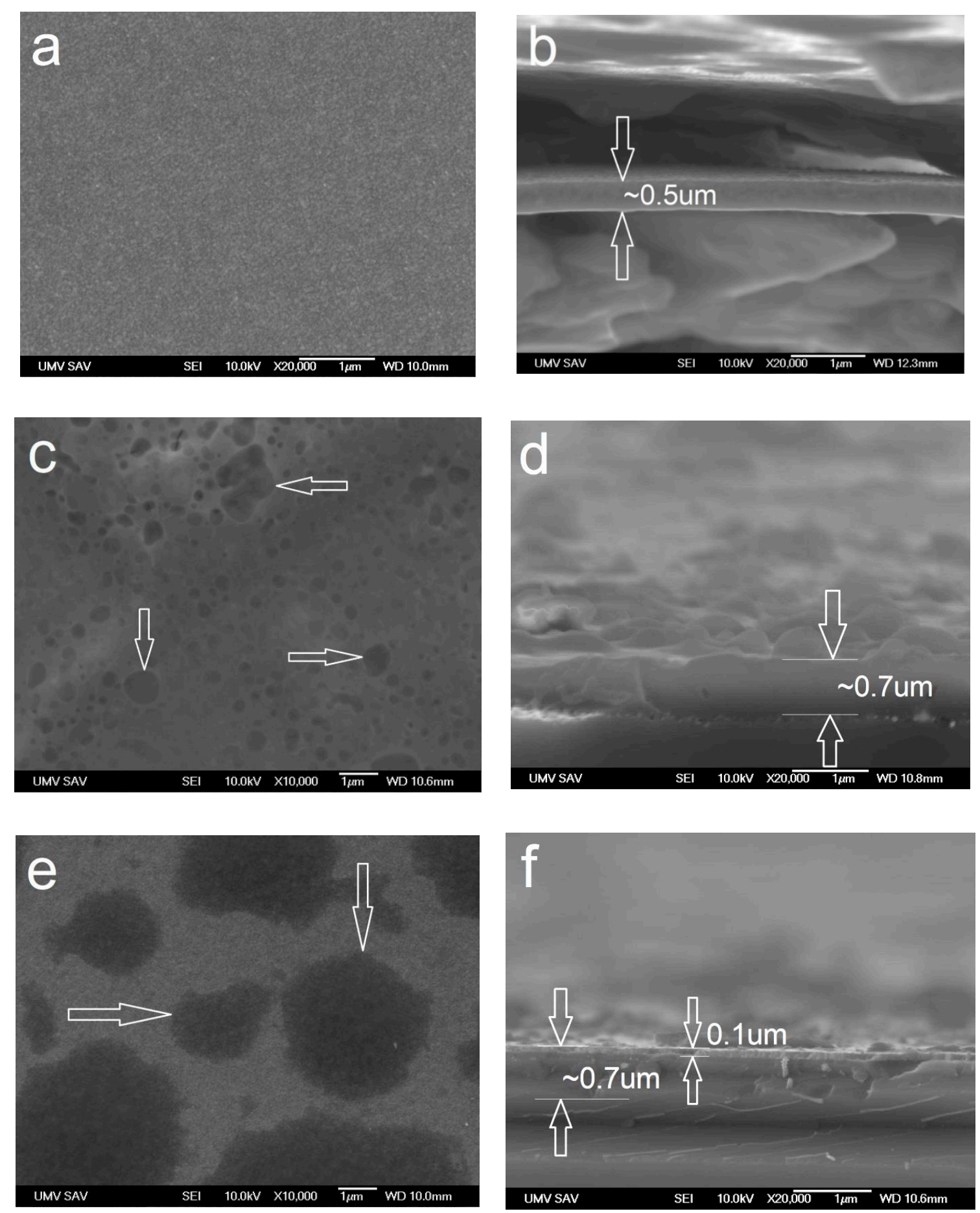

Figure 9. Morphology of the surface and cross-sectional brake of WC/C coating (based on SEM images) deposited with $\mathrm{N}_{2}$ (added gas): (a,b) RT and annealed at (c,d) $500{ }^{\circ} \mathrm{C}$ and $(\mathbf{e}, \mathbf{f}) 800{ }^{\circ} \mathrm{C}$. 


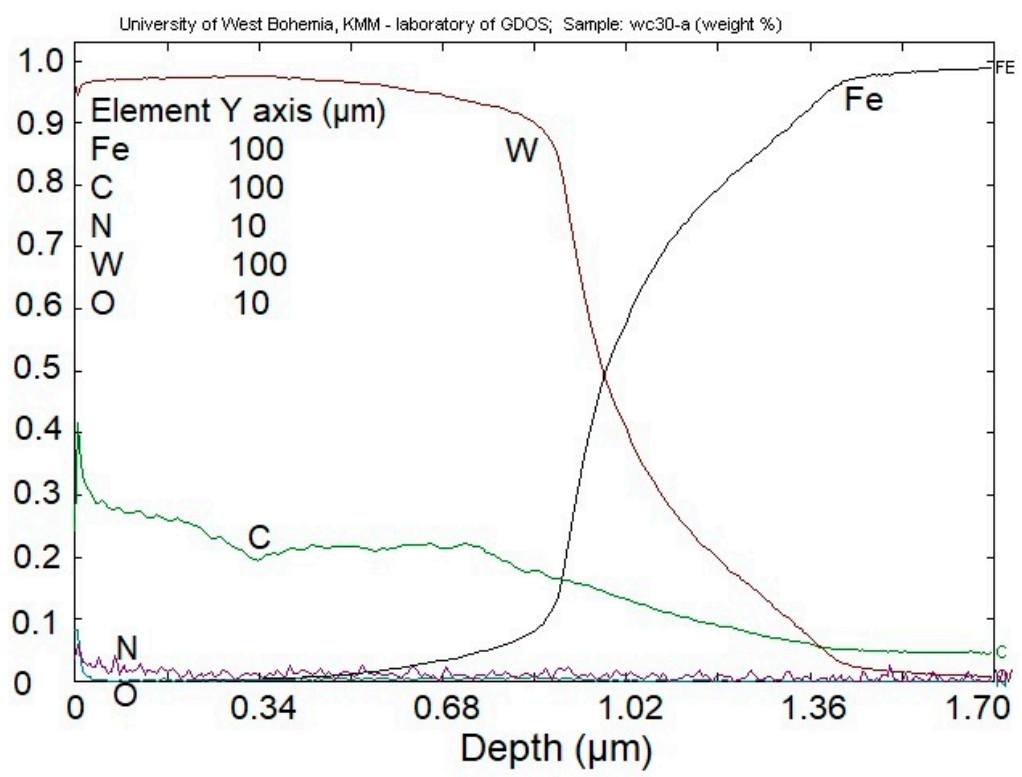

Figure 10. Cross-sectional chemical profile of WC/C coating.

\subsubsection{Phase Analysis}

Before annealing, the WC/C coating showed its amorphous character with nanostructured morphology (Figure 11). Phase analysis of the coating after annealing at a temperature of $500{ }^{\circ} \mathrm{C}$ is referring to its crystal character. The carbide phase of $W_{1-x}$ and $W_{3}$ and a wide amorphous peak are present in the coating. A similar character is shown by an RTG recording after annealing at a temperature of $800{ }^{\circ} \mathrm{C}$. Maximums of amorphous and carbide $\mathrm{WC}_{1-\mathrm{x}}$ and oxidic $\mathrm{WO}_{3}$ decreased. A glassy amorphous structure can be shown by using a cross-sectional view, which is in accordance with Reference [5], with a suggestion of the creation of crystal structure (Figure 9f).

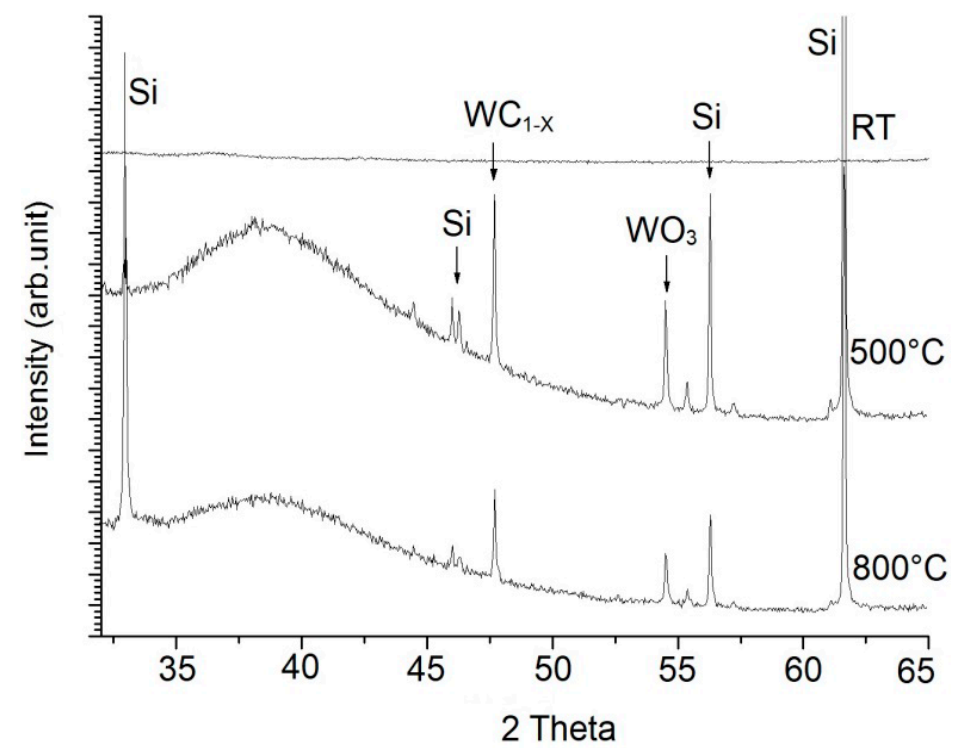

Figure 11. X-ray diffraction scans of WC/C coatings at RT, after annealing at 500 and $800{ }^{\circ} \mathrm{C}$; Si phase.

\subsubsection{Mechanical Properties and COF}

The measured hardness $\mathrm{H}_{\mathrm{IT}}=28 \mathrm{GPa}$ was in agreement with the case of the WC/C coating deposited with Ar (Figure 8a), which is one-fifth less as in Reference [4] (24.5 \pm 1.2 GPa), where DCMS with $\mathrm{N}_{2}$ added gas was used, and 50\% less when compared to Reference [14] (13.5 $\left.\pm 1.0 \mathrm{GPa}\right)$, where RFMS with $\mathrm{N}_{2}$ carrying gas was used. Hardness decreased by $45 \%$, down to $10 \mathrm{GPa}$, after annealing at 
a temperature of $500{ }^{\circ} \mathrm{C}$, which is much more than in the argon process. After further annealing at temperatures of 500 and $800{ }^{\circ} \mathrm{C}$ (respectively), hardness slightly increased to $12 \mathrm{GPa}$. $\mathrm{N}_{2}$ in deposited $\mathrm{WC} / \mathrm{C}$ coating caused a decrease of COF of the evaluated coating deposited with Ar, from $0.77 \pm 0.02$ down to $0.59 \pm 0.03$. That is $45 \%$ less, compared to the coating deposited with Ar (Figure 8b). It is simultaneously ca. 50\% less when compared with what was measured in Reference [4] $(0.26 \pm 1.2 \mathrm{GPa})$ and Reference [15] $(0.23 \pm 0.2 \mathrm{GPa})$. On the other side, COF deposited with the $\mathrm{W}$ carbonyl without added gas is $50 \%$ lower. After the process of annealing at temperatures of 200,500 , and $800{ }^{\circ} \mathrm{C}$, respectively, COF decreased to $0.37 \pm 0.06$, which is close to the WC/C coating deposited with the Ar. A decrease in COF could be caused by a decrease in hardness after annealing, while a decrease in hardness after annealing could have caused an increase in the content of $C$ in its graphite form, which acts as a dry lubricant.

\section{Conclusions}

Based on the obtained results, the following could be said:

i. Maximal values (deposition with $\mathrm{W}$ carbonyl as precursor) were $\mathrm{H}_{\mathrm{IT}}=20.9 \pm 2 \mathrm{GPa}$ and $\mathrm{E}_{\mathrm{IT}}=$ $298 \pm 20 \mathrm{GPa}$, with a bias voltage of $-5 \mathrm{kV}$ and pressure of $3.0 \mathrm{~Pa}$. The COF was 0.3.

ii. Additional gases, such as $\mathrm{Ar}$ and $\mathrm{N}_{2}$, significantly increased values of $\mathrm{H}_{\mathrm{IT}}$. $\mathrm{COF}$ value in the case of additional Ar increased more than twofold. Added $\mathrm{N}_{2}$ caused a marked increase of $\mathrm{COF}$ at a slight increase in the value of hardness $\mathrm{H}_{\mathrm{IT}}$.

iii. Sample No. 6 with WC/C coating deposited with added gas Ar is the best sample according to values of hardness and COF. Its hardness is equal to $28.5 \pm 2 \mathrm{GPa}$, which is $33 \%$ greater, as opposed to the coating deposited without added gas ( $c a .20 .9 \mathrm{GPa}$ ). On the other hand, the COF of the coating deposited with $\operatorname{Ar}(c a .0 .8)$ is more than three times greater when compared with the coating deposited without added gas ( $c a .0 .26)$. Therefore, when choosing one of these coatings, it is necessary to consider the conditions of the components' coated surface usage.

iv. During deposition, Ar was built into the coating, which could have caused internal compressive pressure. That could have, in turn, caused an increase of hardness, the opposite of the coating deposited without added gas. In the case of $\mathrm{N}_{2}, \mathrm{H}_{\mathrm{IT}}$ may increase due to the formation of $\mathrm{W}$ nitrides in the coating, which has a higher $\mathrm{H}_{\mathrm{IT}}$ than $\mathrm{W}$.

v. The temperature of annealing in the case of added $\mathrm{N}_{2}$ and Ar caused a dramatic decrease of $\mathrm{H}_{\text {IT }}$. In the case of $\mathrm{Ar}$, the measured $\mathrm{H}_{\mathrm{IT}}$ values were significantly smaller.

vi. In the case of added $\mathrm{Ar}$, the 500 and $800{ }^{\circ} \mathrm{C}$ temperatures of annealing caused a dramatic decrease of $\mathrm{COF}$, from $0.77 \pm 0.02$ to $0.27 \pm 0.05$ and $0.37 \pm 0.06$. In the case of added $\mathrm{N}_{2}$, the annealing temperatures caused a similar decrease in $\mathrm{COF}$.

vii. In the process of annealing in an unprotected atmosphere at the temperatures of 500 and $800{ }^{\circ} \mathrm{C}$, the WC/C coatings were degraded mainly due to oxidation, which was partially accompanied by swelling. WC/C coating deposited with added $\mathrm{Ar}$ and annealed at the temperature of $800{ }^{\circ} \mathrm{C}$ was significantly degraded due to the aforementioned mechanisms.

viii. It is appropriate to use $\mathrm{N}_{2}$ as an added gas, to improve the resistance against oxidation of the WC/C coating deposited using the PECVD method with $\mathrm{W}$ hexacarbonyl.

In the future, it could be useful to aim at the research of the influence of $\mathrm{Si}$ in the form of added gas $\mathrm{SiH}_{4}$ on the mechanical and tribological properties of the WC/C coating. Another interesting topic of research could be the influence of built-in Ar in the WC/C coating deposited from the carbonyl of W on the mentioned properties.

Author Contributions: P.H. deposited WC/C coatings, evaluated SEM analysis of structure of coatings and roughness by AFM; D.K. prepared experiment and wrote this manuscript; K.K. and Ł.K. carried out qualitative phase analysis and performed G.D.O.E.S testing of the chemical analysis of coatings; M.T. and J.M. assisted at 
hardness measurement and analyzed data, and prepared samples for deposition of coatings; J.T., J.H., and M.P. conducted Ball-on-Disc testing. All authors have read and agreed to the published version of the manuscript.

Funding: This research was funded by the Ministry of Education of the Slovak Republic VEGA No. 1/0432/17 and of the Slovak Research and Development Agency APVV-17-0258 and APVV-16-0359 and the APC was funded by the Slovak Research and Development Agency.

Acknowledgments: This research was supported by the scientific grant agency of the Ministry of Education, Science, Research and Sport of the Slovak Republic, grant number VEGA No. 1/0432/17 and of the Slovak Research and Development Agency grant numbers APVV-17-0258 and APVV-16-0359.

Conflicts of Interest: The authors declare no conflict of interest.

\section{References}

1. Bhushan, B.; Gupta, B.K. Handbook of Tribology: Materials, Coatings, and Surface Treatments; McGraw-Hill: New York, NY, USA, 1991; p. 1643.

2. Makowka, M.; Pawlak, W.; Konarski, P.; Wendler, B. Hydrogen content influence on tribological properties of nc-WC/a-C:H coatings. Diam. Relat. Mater. 2016, 67, 16-25. [CrossRef]

3. Lofaj, F.; Kabátová, M.; Klich, M.; Vaňa, D.; Dobrovodský, J. The comparison of structure and properties in DC magnetron sputtered and HiPIMS W-C:H coatings with different hydrogen content. Ceram. Int. 2019, 45, 9502-9514. [CrossRef]

4. Horňák, P.; Kottfer, D.; Kaczmarek, L.; Kianicová, M.; Balko, J.; Rehák, F.; Pekarčíková, M.; Čižnár, P. The effect of pressure, bias voltage and annealing temperature on $\mathrm{N}_{2}$ and $\mathrm{N}_{2}+\mathrm{SiH}_{4}$ doped WC/C DC magnetron sputtered layers. Ceram. Silik. 2018, 62, 97-107. [CrossRef]

5. Abad, M.D.; Muñoz-Márquez, M.A.; El Mrabet, S.; Justo, A.; Sánchez-López, J.C. Tailored synthesis of nanostructured WC/a-C layers by dual magnetron sputtering. Surf. Coat. Technol. 2010, 204, 3490-3500. [CrossRef]

6. Zhou, S.G.; Wang, L.; Wang, S.C.; Xue, Q. Comparative study of simplex doped nc-WC/a-C and duplex doped nc- WC/a-C(Al) nanocomposite layers. Appl. Surf. Sci. 2011, 257, 6971-6979. [CrossRef]

7. Kosinskiy, M.; Ahmed, S.I.U.; Liu, Y.; Gubisch, M.; Mastylo, R.; Spiess, L.; Schaefer, J.A. Friction and wear properties of WC/C nano-scale multilayer layers on technical surfaces. Tribol. Lett. 2011, 44, 89-98. [CrossRef]

8. Agudelo-Morimitsu, L.C.; DeLaRoche, J.; Escobar, D.; Ospina, R.; Restrepo-Parra, E. Substrate heating and post-annealing effect on tungsten/tungsten carbide bilayers grown by non-reactive DC magnetron sputtering. Ceram. Int. 2013, 39, 7355-7365. [CrossRef]

9. El Mrabet, S.; Abad, M.D.; Sánchez-López, J.C. Identification of the wear mechanism on WC/C nanostructured coatings. Surf. Coat. Technol. 2011, 206, 1913-1920. [CrossRef]

10. Novák, M.; Lofaj, F.; Hviščová, P.; Podoba, R.; Haršáni, M.; Sahul, M.; Čaplovič, L'. Nanohardness of DC magnetron sputtered $\mathrm{W}-\mathrm{C}$ layers as a function of composition and residual stresses. Key Eng. Mater. 2015, 662, 107-110. [CrossRef]

11. Park, Y.S.; Park, Y.; Jung, H.; Jung, T.H.; Lim, D.G.; Choi, W.S. Tribological properties of a-C:W film deposited by radio frequency magnetron Co-sputtering method. Thin Solid Film. 2012, 521, 107-111. [CrossRef]

12. Li, Y.; Zhang, A.; Li, G. The influence of microstructure on mechanical property of polytypic TiC/WC nanomultilayers. Vacuum 2015, 117, 23-26. [CrossRef]

13. Zhao, H.; Ni, Z.; Ye, F. Effect of carbon content on structure and properties of WCN coatings prepared by RF magnetron sputtering. Surf. Coat. Technol. 2016, 287, 129-137. [CrossRef]

14. Hornak, P.; Kottfer, D.; Kaczmarek, L.; Kyziol, K.; Vavro, J.; Klich, M.; Trebuna, J.; Vrabel, M.; Frankova, M. Microstructure and mechanical properties of annealed WCC coatings deposited with different gas mixtures in an RFMS process. Ceram. Silikáty 2019, 63, 213-222. [CrossRef]

15. Lofaj, F.; Kvetková, L.; Hviščová, P.; Gregor, M.; Ferdinandy, M. Reactive processes in the high target utilization sputtering (HiTUS) W-C based coatings. J. Eur. Ceram. Soc. 2016, 36, 3029-3040. [CrossRef]

16. Gesheva, K.A.; Vlakhov, E.S.; Stoyanov, G.I.; Beshkod, G.D.; Marinov, M. Deposition CVD-tungsten and characterization of and tungsten carbonitrides on (100) Si. Ceram. Int. 1996, 22, 87-89. [CrossRef]

17. Neto, M.A.; Silva, E.L.; Fernandes, A.J.S.; Oliveira, F.J.; Silva, R.F. Deposition of $\alpha$-WC/a-C nanocomposite thin films by hot-filament CVD. Surf. Coat. Technol. 2011, 206, 103-106. [CrossRef] 
18. Gesheva, K.; Abrosimova, V.; Beshkov, G. CVD carbonyl thin films of tungsten and molybdenum and their silicides-a good alternative to CVD fluoride tungsten technology. J. Phys. IV 1991, 2, 865-871. [CrossRef]

19. Sagalovych, A.; Popov, V.; Sagalovych, V.; Dudnik, S.; Popenchuk, R. Development of the chemical vapor deposition process for applying molybdenum coatings on the components in assembly and engine construction. East.Eur. J. Enterp. Technol. 2020, 2, 6-15. [CrossRef]

20. Erokhin, M.N.; Kazantsev, S.P.; Chupyatov, N.N. Wear-resistance of carbide-containing chrome coatings obtained from gas phase (in Russian). Vestn. Fed. State Educ. Inst. High. Prof. Educ. Mosc. State Agroeng. Univ. Named VP Goryachkin 2017, 5, 48-53.

21. Ferdinandy, M.; Lofaj, F.; Dusza, J.; Kottfer, D. Preparation of WC coatings by W(CO $)_{6}$ decomposition using PE CVD method (in Slovak). Chem. Lett. 2011, 105, s442-s444.

22. Lofaj, F.; Ferdinandy, M.; Cempura, G.; Horňák, P.; Vnouček, M. Transfer film in a friction contact in the nanocomposite WC-C coatings. J. Aust. Ceram. Soc. 2013, 49, 34-43.

23. Lofaj, F.; Ferdinandy, M.; Kottfer, D.; Dusza, J.; Němeček, J. Tribological properties of the Cr-C and W-C based PECVD nanocomposite coatings (CD room). In Proceedings of the 11th Conference (ECERS 2009), Krakow, Poland, 20-25 June 2009; pp. 642-646.

24. Ferdinandy, M.; Kottfer, D.; Hviščová, P.; Balko, J. Preparation of WCrC coatings by W(CO)6 and Cr(CO)6 decomposition using PECVD method (in Slovak). In Proceedings of the 14th Conference Layers and Coatings, Trenčianska Teplá, Slovakia, 19-20 October 2015; pp. 87-89.

25. Usoltsev, I.; Eichler, R.; Wang, Y.; Even, J.; Yakushev, A.; Haba, H.; Asai, M.; Brand, H.; Di Nitto, A.; Düllmann, C.E.; et al. Decomposition studies of group 6 hexacarbonyl complexes. Part 1: Production and decomposition of $\mathrm{Mo}(\mathrm{CO})_{6}$ and $\mathrm{W}(\mathrm{CO})_{6}$. Radiochim. Acta 2015, 104, 141-151. [CrossRef]

26. Rezuchina, T.N.; Švyrev, V.V. Saturated vapor pressure and sublimation temperature of $\mathrm{Mo}(\mathrm{CO})_{6}$ and $\mathrm{W}(\mathrm{CO})_{6}$ (in Russian). Vestn. Mosk. Univ. 1952, 6, 41-46.

27. Garner, M.L.; Chandra, D.; Lau, K.H. Low-temperature vapor pressures of W-, Cr-, and Co-carbonyls. J. Phase Equilibria 1995, 16, 24-29. [CrossRef]

28. Chellappa, R.; Chandra, D. Assessment of vapor pressure data of solid metal carbonyls. J. Chem. Thermodyn. 2005, 37, 377-387. [CrossRef]

29. Toby, B.H. CMPR-A powder diffraction toolkit. J. Appl. Crystallogr. 2005, 38, 1040-1041. [CrossRef]

30. Lofaj, F.; Kaganovskii, Y.S. Kinetics of WC-Co oxidation accompanied by swelling. J. Mater. Sci. 1995, 30, 1811-1817. [CrossRef]

31. Choy, K.L. Chemical vapour deposition of coatings. Prog. Mater. Sci. 2003, 48, 57-170. [CrossRef] 